\title{
Literatura infantil publicada em Portugal e diálogo intergeracional'
}

\author{
Children's Literature Published in Portugal \\ and Intergenerational Dialogue
}

\author{
FERNANDO AZEVEDO \\ Universidad do Minho \\ Portugal \\ fraga@ie.uminho.pt \\ MOISÉS SELFA SASTRE \\ Universidad de Leida \\ España \\ mselfa@didesp.udl.cat
}

Recibido: O3-II-2OI4; aceptado: I6-OI-2OI5)

Resumo. Este artigo analisa algumas representações literárias dos avós e dos netos na literatura infantil publicada em Portugal depois do ano 2000. Parte dos textos é de autores portugueses, sendo outros de autores estrangeiros traduzidos. Do conjunto de textos selecionados, destacam-se, como principais traços semânticos, noções como a de cumplicidade intergeracional, enorme carinho e a visão do idoso enquanto iniciador dos mais novos no conhecimento do mundo.
Abstract. This paper examines some of the literary representations of grandparents and grandchildren in children's literature published in Portugal after 2000. Some of these texts are from Portuguese authors; others are from authors that have been translated to Portuguese language. Among the set of selected texts, there are several major semantic features: the intergenerational complicity, the great affection between grandparents and their children and the vision of the elderly as initiators of the younger into the knowledge of world.

Keywords: Grandparents; children's literature; values.

Palavras-chave: Avós; literatura infantil; valores.

\footnotetext{
${ }^{\text {I }}$ Para citar este artículo: Azevedo, Fernando y Selfa Sastre, Moisés (2015). Literatura infantil publicada em Portugal e diálogo intergeracional. Alabe 11. [www.revistaalabe.com]

DOI: IO.I5645/Alabe.20I5.II.4
} 


\section{I - Introdução}

Embora o conceito de família possa ser perspectivado como histórica e sociologicamente variável, com representações, valores e ideologias nem sempre coincidentes (Cecil \& Roberts, I998; Alston, 20o8), ele constitui hoje um elemento nuclear no processo educativo das crianças. O agregado familiar tem vindo a sofrer alterações várias, em larga medida decorrentes da modificação das condições históricas, económicas e socioculturais dominantes na sociedade portuguesa.

A literatura infantil, enquanto conjunto de textos que dialoga mediatamente com a semiosfera, explicita, interroga e analisa determinadas configurações familiares, ajudando os seus leitores a refletir acerca dos modelos de sociedade que temos e que desejamos para os nossos filhos, como bem sublinhou Alba Alonso Feijoo (20I3).

Na reflexão lata sobre a família, o lugar simbólico ocupado pelos idosos merece uma atenção privilegiada, na medida em que possibilita abordar questões ligadas à dimensão educativa dos mais novos, no que respeita quer aos saberes partilhados entre gerações, quer aos rituais da morte e da vida ${ }^{2}$. Alfredo Hoyuelos Planillo (2004), num ensaio sobre o ponto de vista das crianças relativamente aos papéis dos idosos na família, assinala que estes desempenham, em contexto familiar, relevantes lugares: eles são, com efeito, os cuidadores das crianças, os seus companheiros de jogos, os contadores de histórias e transmissores de valores ético-morais, os modelos de envelhecimento, mas também os modelos do primeiro contacto destes com a morte, a ajuda nos momentos de crise, os símbolos do amor incondicional, os confidentes e companheiros das crianças.

Gloria Bazzocchi (20I3), numa reflexão sobre o papel dos avós na literatura infantil espanhola e italiana, realça que o idoso aparece, com frequência, como encarnação da voz do passado, da voz da experiência e da sabedoria, no fundo, dos valores universais da lealdade, respeito e compreensão pelos outros. O idoso, enquanto representante de uma certa memória coletiva, mantém uma relação direta e afetiva com a criança, apresentando-se como um companheiro das suas brincadeiras e como o ser que a ajuda a crescer e a formar-se enquanto sujeito. O avô é, muitas vezes, o contador de histórias, aquele que inicia o neto nas aventuras da linguagem e das palavras, no fundo, a pessoa que, com a sua presença, ajuda a criança a descobrir o mundo, sendo que, como sublinha Gloria Bazzocchi (2OI3: 65), esta descoberta iniciática é, muito frequentemente, dada a ler através da metáfora do passeio ou da viagem. O tópos da deslocação espacial possibilita condensar, em meia dúzia de frases, um conhecimento iniciático matricial fundamental para o neto enquanto sujeito e enquanto pessoa. Esta relação é, porém, também vista em sentido inverso: a cumplicidade profunda entre avós e netos faz com que sejam os mais novos, em determinadas situações, a devolver aos idosos parte do carinho e do tesouro da imaginação e da sabedoria que, graças a eles, têm nos seus corações.

\footnotetext{
${ }^{2}$ Maxine Walker (I978: I88) assinala que "birth, puberty, mating, and death are the universal verities of mankind. All cultures have developed mystic rites to help their people cope with the guilts and fears that tend to be aroused by these natural stages. A preoccupation with the events themselves and with associated social ritual has been the foundation stone of literature."
} 
Iria Míguez (20I3), numa reflexão sobre Fina Casalderrey, uma das escritoras mais reconhecidas, traduzidas e premiadas da Literatura Infantil e Juvenil galega atual, assinala que os avós - personagens adultos, por oposição às crianças ou aos jovens - são o símbolo da sabedoria e da experiência, motivo pelo qual são, muitas vezes, percebidos como confidentes dos mais novos ou o último reduto capaz de solucionar qualquer problema ou conflito: "El abuelo, por tanto, se convierte en el lazo de unión de sus nietos; un vínculo alimentado de esa complicidad, de esa confidencialidad entre niños y ancianos" (Míguez, 20I3: 243).

Mas o idoso partilha com a criança também uma outra faceta. Como assinala Cesari Lusso (2004: 49), quer o idoso quer a criança como que assumem uma certa faceta de seres "marginais", seja pelo abandono da vida ativa (no caso do idoso), seja pela ainda não consideração da criança como sujeito detentor de opinião e de capacidade de ação, e nesta aproximação mútua ambos encontram pontes de diálogo frutuoso. O sociólogo Paulo de Salles Oliveira (I999) enfatiza, a este respeito, que, tratando-se de grupos etários que são inferiorizados socialmente, eles mostram-se capazes de criar, em conjunto, outras práticas de convivência e de reinventar as suas vidas com um saber-estar de "resistência" face às práticas opressoras.

Nesta perspetiva, a socialização do saber na convivência entre gerações é um dos aspetos mais marcantes nos textos da literatura infantil que abordam a relação entre avôs e netos, como explicita Célia Regina Delácio Fernandes (2013).

Este ensaio apresenta uma visão geral acerca do tratamento que a literatura infantil publicada em Portugal, depois do ano 2000, faz da imagem dos avós, dos seus lugares na sociedade e dos valores de que eles são portadores para os mais novos.

\section{2 - Como são literariamente representados os avós na literatura infantil publicada em Portugal?}

Os avós, embora perdendo alguma da relevância e estatuto que desempenharam, tradicionalmente, nas sociedade agrárias e não industrializadas, são, ainda hoje, concebidos como elementos importantes na vida das crianças. Se os pais estabelecem os limites e as regras que devem ser seguidas, os avós desempenham um outro papel, talvez mais próximo, talvez mais cúmplice com os netos. Se os pais fazem de pais, os avós, muitas vezes, desempenham o papel de amigos para as crianças, cheios de histórias e também de tempo e com vontade de compartilhar. O binómio avô-neto é um dos mais presentes na literatura infantil. Podemos encontrar idosos que estão sozinhos, avós que têm muitas histórias para contar, avós teimosos, avós que perdem a memória, avós que começam uma nova vida, que procuram amigos, avós que fazem mais ou menos o que toda a gente faz.

Na generalidade, os textos apresentam-nos como detentores de uma sabedoria iniciática e de uma relação de cumplicidade afectiva com os seus netos e, no caso de, pela sua diferença etária, já não estarem presentes, a imagem dos avós é recordada com muita 
afeição e saudade. Os avós são como que os representantes máximos da autenticidade e a reserva simbólica dos valores que caracterizam e definem a humanidade.

No panorama editorial português existem alguns títulos que abordam, com perspetivas diferenciadas, este diálogo intergeracional. Avós e netos fazem-nos sorrir em cada página, apresentam, com harmonia de ternura e humor, situações da vida quotidiana, na qual avós e netos desempenham um papel que toda a gente já experimentou. Dos textos aqui coligidos, poderemos destacar elementos surpreendentes e inspiradores.

Escrito num registo afetivo, e muito próximo do quotidiano, com exempla de situações onde a recordação da imagem do avô é materializável, o álbum narrativo $O A v o ̂ e$ $E u$, de Maria Teresa Gonzalez (2008), com ilustrações de Fátima Afonso, evoca essa figura tutelar e quase demiúrgica na perspectiva da neta. A capa exibe um avô idoso, marcado pelos seus cabelos brancos, à sombra e sob proteção do qual se recolhem duas crianças, provavelmente os seus netos. O álbum é antecedido de uma epígrafe, da autoria da Irmã Wendy, no Livro dos Santos, que sugere a leitura do texto à luz de uma chave polissémica: "Ser sano é viver no mundo real e ir ao encontro das pessoas que Deus colocou no nosso caminho e amá-las. // Para muitos de nós, essas pessoas são a nossa própria família.”

Aos olhos da criança, o avô é o elemento desencadeador de todas as aprendizagens dos netos. Ele apresenta-se, com efeito, como um ser simultaneamente iniciador dos mais jovens na aprendizagem da vida bem como um ser que vela pela sua proteção: "No verão é o avô que nos leva a descobrir algumas maravilhas da natureza e é ele que nos dá lições de natação quando vamos à praia ou à piscina." (Gonzalez, 2008: ı2-I3). Toda a organização do álbum se faz por meio de uma dupla página, onde predomina a mancha gráfica, que ilustra e expande um curto enunciado, frequentemente de natureza afetiva. E a figura é evocada através de um percurso que vai definindo aquele que é o entendimento comum da figura do avô: a idade, a capacidade ou a dificuldade de locomoção, a aposentação, a sabedoria alargada, a disponibilidade de tempo para o lazer, a capacidade de ensinar aspetos úteis da vida aos netos, o carinho e a profunda ternura para com eles.

O texto encerra com uma confissão afetiva da narradora, confissão essa que, situada num plano ficcional, dialoga com realidades do mundo empírico e histórico-factual: "Há muitos avôs no Mundo, mas, por tudo o que me tens ensinado, posso dizer que nenhum é como tu, QUERIDO AVÔ!” (Gonzalez, 2008: 42).

Em O Relógio da Minha Avó (McCaughrean, 2005), com ilustrações de Stephen Lambert, apresenta-se outro ponto de vista da neta face à avó: os objetos da sua casa e as suas idiossincrasias, a sua sabedoria de vida e a partilha afetiva de um saber muito próprio cujos traços, frequentemente não condicionados pela temporalidade do mundo histórico-factual, se revelam dotados de uma sabedoria fundacional:

Um minuto é o tempo que levamos a pensar em qualquer coisa e a dizê-lo por palavras. Em dois, consigo ler uma página num livro.

Uma hora é o tempo que a água da banheira leva a arrefecer... Ou o tempo que o avô demora a ler o jornal.

(McCaughrean, 2005: 9) 
Ou o que gastamos os dois a passear o cão.

(McCaughrean, 2005: Io)

De manhã, sei que horas são pelas sombras da magnólia, que são mais curtas.

Quando voltam a aumentar, é sinal que chegou o entardecer.

(McCaughrean, 2005: I3)

Sabes que o dia acabou quando a tua mãe te dá um beijo de boa noite, não é?

(McCaughrean, 2005: I5)

A obra, recomendada pelo Plano Nacional de Leitura, mostra aos seus leitores que, com a presença e a ajuda dos mais velhos, não há dificuldades que possam surgir, já que tudo se torna bastante mais simples e acessível.

Vencedor do prémio da Fundação Nacional do Livro Infantil e Juvenil (Brasil), melhor livro na categoria de literatura portuguesa - produção de 2OIO, o álbum narrativo Avô, conta outra vez (Letria, 2008) apresenta um conjunto de quadras que testemunham a relação afetiva que une o avô ao neto: a ternura dos abraços, a aprendizagem das primeiras palavras, a conquista progressiva da autonomia, o conhecimento do mundo, a partilha de uma memória, a continuidade das gerações, a ternura e o carinho, a partilha do secreto entendimento e, finalmente, a expressão sublime da saudade. O conjunto das várias quadras rememora e reitera, com incidência afetiva, o vocativo dirigido pelo neto ao avô para que este, presentificando a situação passada, reconte, mais uma vez, as suas histórias encantatórias que tanto seduziram e maravilharam a criança: “Ó avô, conta outra vez".

A capa, elemento configurador de um horizonte de expectativas por excelência, apresenta, num fundo amarelo indefinido, duas figuras de costas: uma figura adulta e uma figura criança. O primeiro, protegendo o segundo, e observando ambos um balão ao longe, que se eleva num espaço e tempo exotópicos e exocrónicos. Articulando o desenho com o título do álbum, deduz-se que se tratará do avô e do neto e que a relação afetiva que une as duas personagens, associada à simplicidade da atitude da contemplação partilhada, exibe um dos traços matriciais da obra.

No álbum narrativo Querida Avô, escrito e ilustrado pela autora suíça Birte Müller (2004), aborda-se uma questão importante na vida de uma criança: onde está a alma da avó que faleceu? Incapaz de compreender racionalmente a súbita ausência da avó, a jovem Felipa, imbuída pela saudade pungente, indaga junto dos animais que lhe são mais próximos aonde se poderá encontrar a avó. Escrito num registo predominantemente afetivo, o leitor é convidado a percorrer os lugares mais familiares da jovem aldeã (a casa, o curral dos animais, a montanha), conhecendo a ação discursiva que ela estabelece com os animais que contextualizam a sua vivência: o burrico, os porcos, os lamas.

Teresa Mendes (20I3) realça, num artigo sobre a morte dos avós na literatura infantil, que neste álbum é visível a dimensão espiritualizada da morte e que a neta, apesar de triste, aceita com normalidade a morte da avó, sem drama, angústia ou revolta. 
Este é, com efeito, um álbum que, para além de abordar a saudade da jovem neta face à morte da avó, permite igualmente ajudar o leitor a conhecer contextos de diversidade cultural ${ }^{3}$, nomeadamente tradições ligadas ao culto dos mortos e à Festa de Todos os Santos (comemorada a i Novembro), num país da América do Sul. Aliás, desde a capa que a indumentária da criança remete o leitor para uma certa cultura, aspecto que é reforçado pela explicação metatextual, no final da narrativa, da responsabilidade da autora, em que a mesma refere tratar-se de uma recordação/homenagem à Festa de Todos os Santos, que ocorre numa aldeia dos Andes (Bolívia).

No álbum narrativo Um Avô Inesquecível (Westera, 2005), obra recomendada pelo Plano Nacional de Leitura português, evoca-se, com emoção, a recordação da figura carinhosa, próxima e inesquecível do avô. A narrativa inicia-se no dia do seu funeral, poucos momentos antes do caixão baixar à terra. João, o neto, recorda, com lágrimas nos olhos, um conjunto de episódios marcantes na sua ainda curta vida: as brincadeiras ("Ele era um cowboy na pradaria e o avô era o cavalo", a construção de um barco de piratas, o divertimento na praia), o espírito de aventura e de cumplicidade, a iniciação tutelada pelo avô (o aprender a andar de bicicleta), e toda uma série de pequenos gestos partilhados, onde sobressaem as diferenças entre os seus mundos e o mundo dos outros adultos:

João não sabia que os crescidos podiam andar tão devagar. Nas ruas da sua cidade andavam sempre a correr...

Olha para o caixão onde está o avô.

Há tantas coisas que gostaria de lhe perguntar:

Se está escuro dentro do caixão.

Se morrer dói.

Se o avô está no céu, como diz a tia Luísa.

E como é o céu.

Mas o tio Jorge diz que o céu não existe.

Quem é que está certo, avô?

Lentamente, o caixão é descido para a cova.

Os crescidos atiram mãos-cheias de terra para a cova.

- Eu não quero, - diz João, escondendo-se atrás da mãe.

(Westera, 2005: s/p)

Teresa Mendes (2OI3: II2I) assinala que o lenço de cor vermelho-sangue, que contrasta com a neutralidade do tom sépia dominante (expressão plástica de um certo vazio afetivo e existencial que a morte do avô provoca no neto), "é o sinal de que a vida continua e de que os afetos perduram muito para além da partida daqueles que mais amamos.”

3 Cecil \& Roberts (I998: xiii) sublinham que, quando confrontada com a história de uma criança de uma outra cultura, ela pode perceber que, apesar das diferenças, há algo que a une ao outro: a afetividade das relações humanas. 
O avô, agora desaparecido é, para o neto, o símbolo da sabedoria e da iniciação ao mundo dos adultos, no fundo a fronteira que marca a transição entre o mundo da infância e da inocência e o mundo da idade adulta, numa alusão com traços de diálogo intertextual ao tempo e aos lugares da infância de Peter Pan, na obra de James Barrie.

Vencedor do Prémio Bissaya Barreto de Literatura para a Infância, no ano de 2008, e recomendado pelo Plano Nacional de Leitura português, o álbum narrativo $O$ Livro da Avó (Silva, 2007) apresenta a perspectiva do neto face à avó e à sua ausência. Num texto singelo e repleto de emoção, o neto relembra a vida, os traços mais característicos, as histórias, as visitas da infância a casa da avó, os momentos de partilha, de festa e de brincadeira, mas também a afectividade e o carinho que o uniam a essa pessoa.

A dor imensa da saudade da ausência é dada a ler predominantemente de modo gráfico. Depois de expressar a ausência inesperada do ser querido, o livro exibe, num primeiro momento, a imagem de um largo oceano, expressão metafórica para as lágrimas copiosas que invadem o neto e que o impedem de falar. Num segundo momento, a dor da ausência e a saudade são expressas pela afirmação, em letras manuscritas, ocupando toda a mancha gráfica da página: "fazes-me falta!"

\section{3-Conclusões}

A literatura infantil apresenta-se, como sublinhou Pedro Cerrillo (2003: 78), como uma literatura predominantemente afetiva. Os seus textos, modelizando o real, mostram-nos que as crianças são sempre vencedoras (Lurie, 1998: 32) e ensinam os seus leitores a perceber o que significa ser humano, os seus traços matriciais e os seus valores fundacionais.

Os textos aqui coligidos demonstram que à pessoa idosa, familiar da criança, é reconhecido um estatuto privilegiado na estrutura familiar. $\mathrm{O}$ avô ou a avó mostram-se detentores de uma sabedoria vivida, de uma capacidade de amar e de partilhar com os mais novos esse saber estar e saber viver, e, quando já não estão fisicamente presentes no mundo dos vivos, eles são objeto de uma saudade aparentemente sem limites. Neste retrato dos mais idosos, a literatura infantil contemporânea, concretizando uma dimensão ética e educativa, mostra-se herdeira de uma longa tradição social e cultural que, nas sociedades agrárias, sempre valorizou o idoso, considerando-o detentor de saberes ancestrais e axiológicos que naturalmente deveriam ser partilhados com as gerações mais jovens.

Assim, a interação da criança com estes textos possibilita-lhe não apenas evocar alguém relevante nas suas experiências de vida, como também encontrar respostas que a podem ajudar a exteriorizar as suas emoções e a lidar com o sofrimento e a saudade dos que já partiram. Os protagonistas dos textos aqui apresentados são uns avós e umas avós muito peculiares, que são concebidos com sensibilidade e ternura, e onde os seus traços, cuidadosamente doseados, se encontram ao serviço da humanidade das personagens. Ou 
seja, estamos perante um uso da ficção que não afasta os protagonistas do mundo empírico e histórico-factual, mas que traz originalidade e se encontra ao serviço da sua personalidade. Da mesma forma, este uso do ficcional faz com que as histórias nunca se tornem previsíveis, mas surpreendam, gerem expectativas e se leiam com prazer.

Atualmente, a literatura goza de um papel de destaque na nossa sociedade, mas mais ainda no caso da literatura infantil, em que a criança, felizmente, está no foco de toda a atenção das gerações mais velhas, graças em parte ao trabalho de autores que, com as suas obras, além de cultivarem a imaginação, nos apresentam modelos a imitar. E entre esses modelos a imitar encontram-se os avós, protagonistas de um tipo de literatura para as gerações mais jovens que sentem uma genuína devoção aos seus antepassados mais próximos e que são a sua autêntica referência de vida pelos valores que encarnam. 


\section{4-Referências}

- Alonso Feijoo, A. (2013). La familia del nuevo niño en la Literatura Infantily Juvenil del siglo XXI. Un estudio de caso: My Princess Boy de Cheryl Kilodavis. En A. M. Ramos \& C. Ferreira Boo (Eds.). La familia en la Literatura Infantil y Juvenil / A família na Literatura Infantil e Juvenil (pp. I5-26). Vigo/Braga: ANILIJELOS/ CIEC-Universidade do Minho.

- Alston, A. (2008). The Family in English Children's Literature. New York and London: Routledge.

- Bazzocchi, G. (20I3). Los ancianos, maestros de vida: la estrecha relación que se establece entre niños y abuelos en la literatura infantil. En A. M. Ramos \& C. Ferreira Boo (Eds.). La familia en la Literatura Infantily Juvenil / A família na Literatura Infantil e Juvenil (pp. 5976). Vigo/Braga: ANILIJELOS/ CIEC-Universidade do Minho.

- Carvalho, M. (2005). A interacção semiótica texto-imagem nas obras impressas e ilustradas de literatura infantil: ler, ver, desconfiar... Tese de mestrado em Estudos da Criança, especialização em Comunicação Visual e Expressão Plástica. Braga: Instituto de Estudos da Criança. Consultado em I4 de abril de 20I4, http://hdl.handle.net/r822/514O.

- Cecil, N. L. \& Roberts, P. L. (1998). Families in Children's Literature: A Resource Guide, Grades 4-8. Englewood: Teacher Ideas Press.

- Cerrillo, P. (2OO3). Literatura infantil y competencia literaria: hacia un ámbito de estudio y investigación propios de la literatura infanto-juvenil (LIJ). En F. Viana; E. Coquet E. \& M. Martins (Eds.). Leitura, literatura infantil e ilustração. Investigação e prática docente (pp. 738I). Braga: Centro de Estudos da Criança - Universidade do Minho.

- Cesari Lusso, V. (2004). Il mestiere di... nonna e nonno. Gioie e conflitti nell'incontro fra tre generazioni. Trento: Edizioni Erickson.

- Fernandes, C. R. D. (20I3). Avós e netos na literatura infantil: vidas compartilhadas. Educação \& Realidade, $3^{8}$ (4), Io89-III2. Consultado em I4 de setembro de 20I4, http:/ /www. scielo.br/scielo.php?script=sci_arttext\&pid=S2I75-623620I3000400005\&lng=en\&tlng $=$ pt. IO.I590/S2I75-623620I3000400005

- Gonzalez, M. T. (2008). O Avô e Eu. Ilust. de Fátima Afonso. Prior Velho: Paulinas.

- Hoyuelos Planillo, A. (2004). Abuelos, Abuelas, Nietos y Nietas. El Punto De Vista Infantil. Indivisa. Boletin de Estudios e Investigación, 5, 35-42. Consultado em 3 de outubro de 2OI4, http://www.redalyc.org/articulo.oa?id=77IOO5O2

- Letria, J. J. \& Letria, A. (2008). Avô, conta outra vez. Porto: Âmbar. 
- Lurie, A. (1998). No se lo cuentes a los mayores. Literatura infantil, espacio subversivo. Madrid: Fundación Germán Sánchez Ruipérez.

- Mccaughrean, G. (2005). O Relógio da Minha Avó. Ilust. de Stephen Lambert. Rio de Mouro: Everest Editora.

- Mendes, T. L. F. (2013). A morte dos avós na literatura infantil: análise de três álbuns ilustrados. Educação \& Realidade, 38 (4), III3-II27. Consultado em 3 de outubro de 20I4, http: / / www.scielo.br/scielo.php?script=sci_arttext\&pid=S2I75-623620I30004000o6\&lng=en \&tlng=pt. IO.I590/S2I75-62362013000400006.

- Míguez, I. (2013). La figura de los abuelos en la narrativa infantil de Fina Casalderrey. En A. M. Ramos \& C. Ferreira Boo (Eds.). La familia en la Literatura Infantil y Juvenil / A família na Literatura Infantil e Juvenil (pp. 239-246). Vigo/Braga: ANILIJELOS/ CIECUniversidade do Minho.

- Müller, B. (2004). Querida Avó. Porto: Âmbar.

- Oliveira, P. S. (1999). Vidas Compartilhadas: cultura e coeducação de gerações na vida cotidiana. São Paulo: Hucitec/FAPESP.

- Silva, L. (2007). OLivro da Avó. Porto: Afrontamento.

- Walker, M. (1978). Last rites for young readers. Children's Literature in Education, 9 (4), I88-I97.

- Westera, B. (2005). Um Avô Inesquecível. Ilust. de Harmen van Straaten. Lisboa: Livros Horizonte. 